\title{
EFFECTS OF PH SOAKING SOLUTIONS AND HYPOXIA/ANAEROBIC TREAMENT ON GABA ACCUMULATION IN GERMINATED MUNG BEAN
}

\author{
Truong Nhat Trung ${ }^{*}$, Nguyen Tuong Danh, Dong Thi Anh Dao \\ Department of Food Technology, VNU-HCMC University of Technology, \\ 268 Ly Thuong Kiet street, District 10, Ho Chi Minh city \\ "Email: nhattrung2510@gmail.com
}

Received: 22 June 2016; Accepted for publication: 20 January 2017

\begin{abstract}
This study investigated the accumulation of $\gamma$-aminobutyric acid (GABA) in mung bean sprouts (Vigna radiata L.) during germination under hypoxia/anaerobic conditions. Raw mung bean seeds were soaked in water at $35^{\circ} \mathrm{C}$ for 8 hours, dried and germinated under aerobic or hypoxia/anaerobic conditions at $35{ }^{\circ} \mathrm{C}$ or $40{ }^{\circ} \mathrm{C}$ for $0,6,12,24,36$ and 48 hours. Free amino acid and GABA contents were measured during the course of germination. Effect of soaking $\mathrm{pH}$ (5.3, 6.3 and 7.3) on GABA content of germinated mung beans under hypoxia/anaerobic condition was also investigated. The other objective of this study was to optimize the culture conditions of GABA production in germinated mung bean. A significant increase $(\mathrm{p}<0.05)$ of GABA content was found in mung bean samples germinated under hypoxia/anaerobic condition. As this result, the combination of soaking $\mathrm{pH} 6.3$ and 12 hour germination at $35{ }^{\circ} \mathrm{C}$ was found to yield the highest GABA content $(1519.07 \pm 19.58 \mathrm{ppm})$. This figure was 1.41 times as high as the content in aerobic condition and 25.32 times as high as the analysis of the raw mung beans. And experimental analysis showed that the optimal condition with aeration treatment for GABA accumulation in germinated mung bean was at a temperature of $36.6^{\circ} \mathrm{C}$, time of $14.5 \mathrm{~h}$ and a pH value of 5.83; the highest GABA yield was $1638.67 \mathrm{ppm}$, which was 27.77 times higher than raw seeds. In conclusion, germinated mung bean is a good source of GABA and hypoxia/anaerobic condition in combination with soaking $\mathrm{pH}$, germination time and temperature can increase significantly GABA content in germinated mung beans.
\end{abstract}

Keywords: germinated mung bean, GABA, free amino acid, hypoxia-anaerobic, aerobic.

\section{INTRODUCTION}

$\gamma$-aminobutyric acid (GABA), a four carbon non-protein amino acid, is found widely in prokaryotic and eukaryotic organisms. Some studies have reported health benefits of GABA such as decrease of blood pressure, neurotransmitter inhibition the central nervous system, alleviation of pain and anxiety $[1,2]$. Therefore, GABA-enriched foods have recently become more popular among consumers. 
Legumes contain many anti-nutritional factors such as phytic acid, hemagglutinin that are not beneficial for human consumption. Germination is an effective way to reduce most of the antinutritional factors in legumes [3] as well as to improve nutritional values like protein solubility index, emulsification capacity and in vitro protein. Moreover, germination process can increase some phenolic compounds, vitamin $\mathrm{C}$ and gamma-amino butyric acid (GABA). Many researchers have reported accumulation of GABA occurring during germination period of rough rice and brown rice [4], barley [5], buckwheat sprouts [6], and mung bean [7].

GABA is synthesized by the decarboxylation reaction of L-glutamic acid through enzymatic activity of glutamic acid decarboxylase (GAD). The generation of GABA can be increased by many stimulating factors including heat shock, mechanical treatment, hypoxia and phytohormones [8].

Mung bean is composed of about $20-24 \%$ protein, and rich in essential amino acids, such as total aromatic amino acids, leucine, isoleucine, and valine, as compared with the FAO/WHO (1973) reference. By the way, glutamic acid, the substrate for enzyme GAD to produce GABA, is one of the most abundant amino acids in legumes such as soybean [9], and mung bean [7, 10]. Because of the important increasing of mung bean in our country and it can be the potential sources for GABA production. However, conditions for GABA production using local breed of mung beans have not been studied before.

This research studied effects of germination conditions, particularly the aerobic and hypoxia-anaerobic conditions, on the accumulation of GABA in mung beans.

\section{MATERIALS AND METHODS}

\subsection{Material and chemicals}

Mung beans (ĐX 208, AVRDC origin) were grown in Dong Nai province, harvested after one month (12 - $13 \%$ moisture content), preserved at $25^{\circ} \mathrm{C}$ in paper box.

Standard Gamma-amino butyric acid, glycine, and ninhydrin were purchased from Merck (Germany). Pure boric acid, borate, sodium hypochlorite, phenol, citric acid and sodium citrate were supplied from Guangdahengyi.Co, Beijing (China).

\subsection{Preparation of germinated mung beans}

Mung beans were soaked in citrate buffer solution $0.1 \mathrm{~N}$ at a ratio of mung bean seeds to buffer solution of $1: 5(\mathrm{w} / \mathrm{v})$ at $35^{\circ} \mathrm{C}$ for 8 hours. After the liquid part was drained, the soaked mung beans were subject to two germination conditions for $0,6,12,24,36,48$ hours.

Germination condition 1 - Aerobic germination:

Twenty grams of soaked mung bean seeds were kept between thick layers of wet cotton cloths, which were then placed in an uncovered petri dish and stored in incubator set at either $35^{\circ} \mathrm{C}$ or $40^{\circ} \mathrm{C}$ for above mentioned time periods. During the germination, the seeds in cotton cloths were regularly sprayed with water.

Germination condition 2 - Hypoxia/anaerobic germination:

The preparation of soaked mung bean seeds was similar to the aerobic germination. However, the petri dish (with a lid) was placed in plastic bag and vacuum packed (vacuum pump speed 1 liter/sec, $5 \mathrm{sec}$ ) and stored in incubator at $35^{\circ} \mathrm{C}$ and $40{ }^{\circ} \mathrm{C}$. 
In both germination conditions, samples of germinated mung beans were taken every 6 hours to analyze total free amino acid and GABA contents.

In the hypoxia/anaerobic germination part, the effect of $\mathrm{pH}$ of the soaking water on GABA content in mung beans under hypoxia-anaerobic condition was also studied. The $\mathrm{pH}$ of soaking water was adjusted to 5.3, 6.3 and 7.3 with citrate buffer solution. The germination was carried out at $35^{\circ} \mathrm{C}$.

\subsection{Analysis of free amino acid and GABA contents}

\subsubsection{Determination of total content of free amino acids}

Free amino acids were analyzed by the ninhydrin colorimetric method [11]. A known weight of mung bean $(10 \mathrm{~g})$ was ground, combined with $25 \mathrm{ml}$ of $70 \%$ ethanol $(\mathrm{v} / \mathrm{v})$ and stirred for 10 minutes. The mixture was centrifuged at $3000 \mathrm{rpm}$ for 10 minutes and the supernatant was collected and transferred to a $250 \mathrm{ml}$ flask. This extraction process was repeated once. The supernatant was evaporated in a rotary vacuum evaporator (BUCHI, Swiss) at $40{ }^{\circ} \mathrm{C}$, and the residue was dissolved in distilled water in a $50 \mathrm{ml}$ volumetric flask. Five millilitre of the solution and $1 \mathrm{ml}$ ninhydrin were added into test tubes, mixed well and heated in a water bath $\left(100{ }^{\circ} \mathrm{C}\right)$ for 5 minutes. The tubes were then cooled in cold water bath and the absorbance was measured in a spectrophotometer at $570 \mathrm{~nm}$. The reagent blank was prepared by using $5 \mathrm{ml}$ of distilled water instead of sample. Total amount of free amino acids was calculated from a standard curve prepared from glycine. The analyses were done in triplicates.

\subsubsection{Determination of GABA content}

GABA contents in germinated mung beans were determined through a colorimetric method [12]. The preparation of sample was similar to the free amino acid up to the point when evaporated residues were dissolved in distilled water. One millilitre of sample along with $0.6 \mathrm{ml}$ of 0.2 molL- $^{1}$ borate buffer solution ( $\mathrm{pH} 9.0$ ), $2 \mathrm{ml}$ phenol $6 \%$ and $1 \mathrm{ml}$ sodium hypochlorite $9 \%$ were added into a test tube. The mixture was boiled in water bath for 10 minutes and then cooled in cold water bath for 20 minutes. The solution was then continually shaken until a blue colour appeared. The coloured sample was colorimetrically measured at $645 \mathrm{~nm}$ wavelength. The amount of GABA was calculated from a standard GABA curve. The analyses were done in triplicates.

\subsection{Statistical analysis and RSM Design}

The results were reported as mean \pm SD. To compare across different germination treatments, one-way ANOVA test followed by the Duncan's multiple range test $(\mathrm{p}<0.05)$ were performed by using statistical package Statgraphics Centurion programme.

The RSM was applied to identify the influence of the three independent variables on GABA content in germinated mung bean and to optimize the culture conditions for GABA production. The experimental design was performed using Modde software version 5.0 (Umetri A, Umea, Sweden)). On the basis of single-factor experiments, the levels of culture temperature (X1), the levels of culture time (X2), and $\mathrm{pH}$ of culture solution were determined as the subject of the research (Table 1). GABA content (Y) was regarded as the response variable. The completed design consisted of 20 experiments including six replicates of the center points (Table 2). GABA content data were analyzed by multiple regression to fit the following second-order equation:

$$
Y=b_{0}+b_{1} X_{1}+b_{2} X_{2}+b_{3} X_{3}+b_{12} X_{1} X_{2}+b_{13} X_{1} X_{3}+b_{23} X_{2} X_{3}+b_{11} X_{1}{ }^{2}+b_{22} X_{2}{ }^{2}+b_{33} X_{3}^{2}
$$


where $Y$ is the measured response, $b_{0}$ denotes the model intercept; $b_{1}, b_{2}, b_{3}, b_{12}, b_{13}, b_{23}, b_{21}$, $\mathrm{b}_{22}, \mathrm{~b}_{33}$ represent the regression coefficients of variables for linear, quadratic, and interaction regression terms, respectively. An analysis of variance (ANOVA) table is generated to determine individual linear, quadratic, and interaction regression coefficients. The significances of all terms in the polynomial relations are examined statistically by computing the F-value at a probability (p) of 0.05 . The regression coefficients are then used to make statistical analyses and to generate contour maps of the regression models.

\section{RESULTS AND DISCUSSION}

\subsection{Effects of germination conditions on moisture content, total amino acids and GABA}

\subsubsection{Moisture Content}

Change in moisture content of germinated mung beans over 48 hour incubation period was investigated under aerobic and anaerobic conditions (Figure 1). The moisture content of germinated seeds quickly increased from $55 \%$ to nearly $63 \%$ during the first 6 hours regardless the oxygen conditions. Then the moisture content of seeds germinated under aerobic condition (A) continued the fast increasing trend until 24 hours, reached $70 \%$ and only slowed down until 48 hours. The highest moisture content under aerobic condition in this experiment was $71-72 \%$ observed at the end of 48 hour incubation.

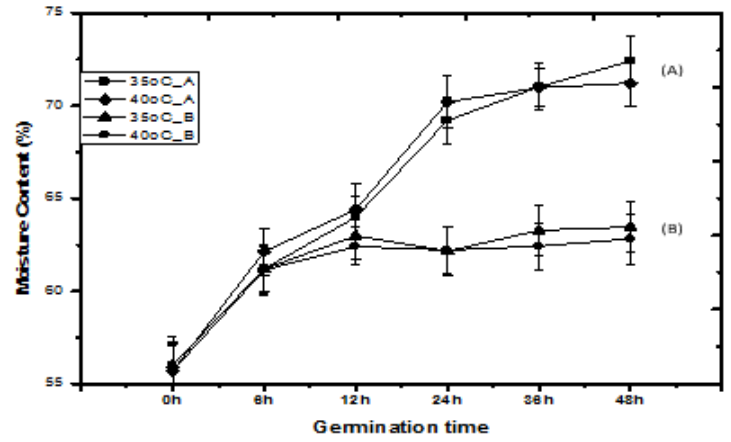

Figure 1. Change of moisture content in two germination conditions with two incubation temperatures.

(A): The aerobic germinated condition; and (B): The hypoxia-anaerobic germinated condition.

However, the opposite trend happened in the anaerobic condition (B) after the first 6 hours of incubation. The moisture content did not change significantly during the next 36 hours and was about $62.5 \%$ at the end of the incubation time (Figure 1).

The higher temperature shows the higher moisture gained. Those indicated the effects of temperature on water absorption of germinated mung bean under non-stress condition. Hence, the moisture content of germinated mung bean slightly increased when the germination time was prolonged, and the lengths of sprouts increased during germination (data not shown).

At the beginning of the germination process, soaked seeds continuously absorbed water from the surrounding medium for metabolic process. Concurrently, enzymes were activated to degrade storage materials for respiration and synthesis of new cells to developing embryo, influenced by the structure of the legume [5]. The germinating sprout consumes and depletes the oxygen dissolving in medium, thus, the oxygen concentration required for the respiration of the plant system becomes a limiting factor. If the oxygen could not be supplemented to medium, the 
sprout will be subjected to a prolonged non-aerated condition and the sprouts will be eventually died off [13]. The water absorption and limited oxygen concentration in the medium could explain the higher moisture content development under aerobic condition.

It was also suggested from this experiment that the hypoxia condition may have started between 6 and 12 hour from the initial point of incubation and the anaerobic condition after 12 hours of germination time. However, it was not possible to estimate the accurate starting time of the hypoxia condition and the anaerobic condition. Alternatively, changes of GABA and total free amino acid contents were further studied under the clearly defined hypoxia-anaerobic condition (B).

\subsubsection{Total content of Free Amino Acid}

The temperature and germination time had significant effects $(\mathrm{p}<0.05)$ on the total content of free amino acid under aerobic condition. The content increased quickly during the first 12 hours of incubation at $35{ }^{\circ} \mathrm{C}$ and the first 36 hours at $40{ }^{\circ} \mathrm{C}$. After 48 hour germination, the total contents of free amino acid were $1.73 \mathrm{~g} / 100 \mathrm{~g}$ DW (dry weight) and $1.79 \mathrm{~g} / 100 \mathrm{~g}$ DW at $35^{\circ} \mathrm{C}$ and $40{ }^{\circ} \mathrm{C}$, respectively, which were about 3.1 times as high as the 0 hour sample.

The high amino acid content resulted from the breakdown of seed components during the germination process. At the same time, there were an increase in the sprout length of germinated mung beans (data not shown), and an increase in the moisture content described earlier (Figure.1).

Velupillai et al. [9] observed that the decreased in total protein content is simultaneous with increased in amino acid content caused by increased level of protease activity. Some previous studies proved germination process caused increase in total amount of essential amino acids in mung bean such as leucine, isoleucine, tryptophan, lysine [5]. A further explanation was done by Nonogaki et al. [14] where the noted protein synthesis occurred during imbibition and that hormonal changes play an important role in achieving the completion of germination.

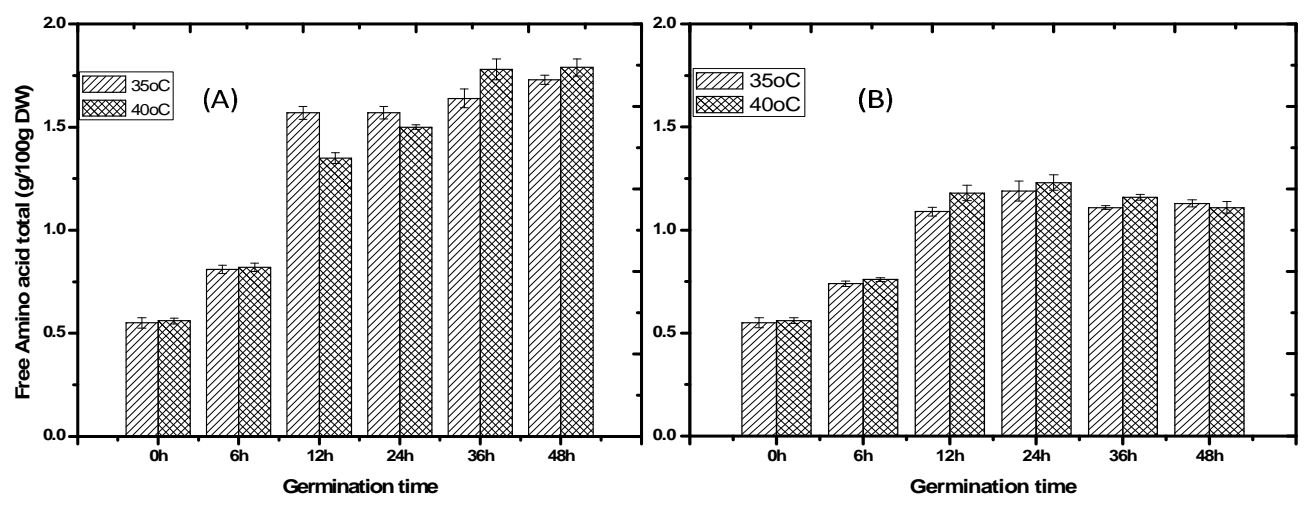

Figure 2. The change of total content of free amino acid in two conditions with two different incubation temperatures. (A): The aerobic germinated condition; and (B): The hypoxia-anaerobic germinated condition.

In the anaerobic condition, the total amount of free amino acid sharply increased in the first 12 hours of incubation, slowly increased from 12 to 24 hours, and slightly decreased between 24 and 48 hours (Figure 2). However, the overall free amino acid content was lower than the value under the aerobic condition. According to our hypothesis above, the hypoxia may have happened between 6 and 12 hours of germination period. The oxygen concentration was depleted and inhibited further germination. In another research, Yang et al. [15] explained that the new 
organs need the degradation of storage protein or amino acids to provide sufficient nitrogen, leading to decrease amino acid content.

Moreover, incubation temperature also affected the amino acid content to a lesser extent than the germination time. Higher temperatures yielded higher amount of free amino acid. The highest total level of free amino acid reached $1.23 \mathrm{~g} / 100 \mathrm{~g}$ DW and $1.20 \mathrm{~g} / 100 \mathrm{~g}$ DW at the temperature $40{ }^{\circ} \mathrm{C}$ and $35^{\circ} \mathrm{C}$ after 24 hours, respectively. These contents were about 2.2 times as high as the 0 hour sample.

\subsubsection{GABA content}

There was significant difference $(\mathrm{p}<0.05)$ in the GABA content when compared between two germination conditions. It is proved that legume seeds germinated under hypoxia treatments boost GABA accumulation [13]. In other hand, some studies also indicated that level of GABA rapidly increase in plant response to various forms of stress that accelerate the accumulation ability of plants, in which the anaerobic condition is the strongest [16]. By the result show in Figure 3, the GABA content in the hypoxia-anaerobic condition contained higher as compared to the aerobic. In general, temperature had significantly impacted to level of GABA.
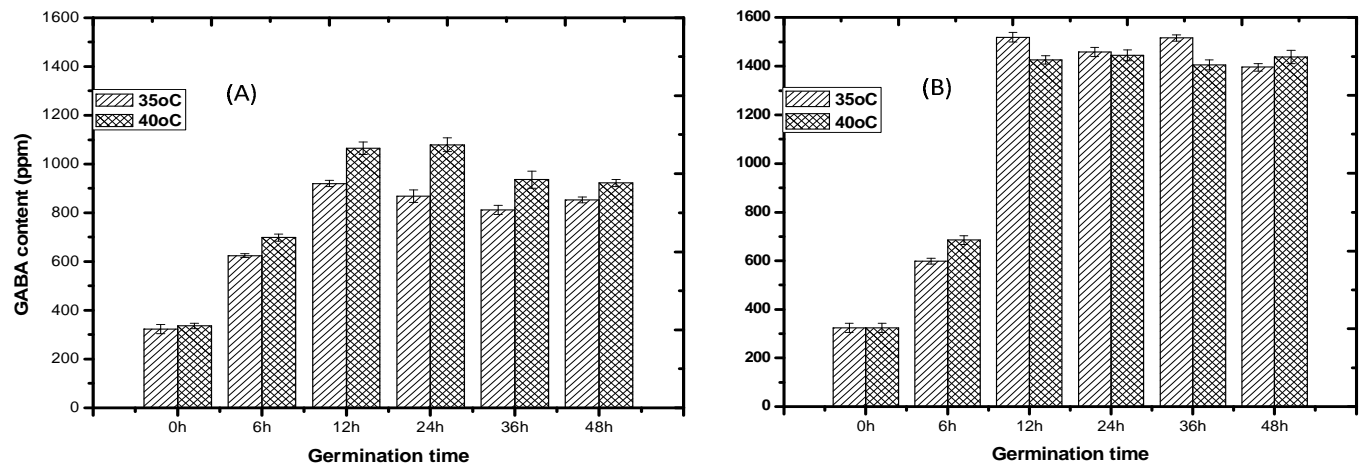

Figure 3. The change of GABA content in two conditions with two incubation temperatures.

(A): The aerobic germinated condition; and (B): The hypoxia-anaerobic germinated condition.

According to Kasarin et al. [7], the highest GABA content was $80.68 \mathrm{ppm}$ in the germinated mung bean after 24 hours of incubation period under aerobic condition. This result is lower than our reports. That is $1078.86 \mathrm{ppm}$ after 24 hours of incubation period at $40{ }^{\circ} \mathrm{C}$ temperature germination (Figure 3). The main reason which Kasarin et al. carried out drying germinated mung bean at $50{ }^{\circ} \mathrm{C}$ in hot oven, leaded to decrease GABA content. However, Kasarin et al. indicated no significant change in the amount GABA after 24 hours of germination period. In our study, the amount GABA slightly decreased after 24 hours of germination at $40{ }^{\circ} \mathrm{C}$, and there is no difference at $35^{\circ} \mathrm{C}(\mathrm{p}>0.05)$. By the way, Swee et al. [17] indicated the GABA content of germinated mung bean extract was $502 \pm 35 \mathrm{ppm}$, lower than our results. This maybe contributed by the different level of GABA-synthesizing enzyme that is present in plants.

In the hypoxia-anaerobic condition, the highest of GABA content achieved $1519.07 \pm$ $19.58 \mathrm{ppm}$ at $35^{\circ} \mathrm{C}$ in the early 12 hours germination. This is 1.41 times higher than the aerobic condition, and 25.32 times higher as compared to mung raw. As the results, there had not significant changes of GABA content between two conditions in the first 6 hours of germination. However, the sharp increase of GABA content is from 6 to 12 hours. On the contrary, the 
highest GABA content achieved at $35{ }^{\circ} \mathrm{C}$, while just achieved $1426.33 \mathrm{ppm}$ at $40{ }^{\circ} \mathrm{C}$ in the same germination time. This indicated that many factors affecting on GABA content and depending on the design of germinated condition. It was depend on the design of germinated condition.

The amount of GABA had a slightly decreased tendency then. This result is agreed with study of Yang et al. [15] in germinate fava bean. Xu et al. [18] explained that reason may be under stress, plant produces some substances such as proline and GABA to resist stress condition. Glutamic can be catalyzed by GAD and converted to GABA, and also can be converted to proline or other substances via a $\Delta^{1}$-pyrroline-5-carboxylic acid (P5C) intermediate formation under the catalysis of $\Delta^{1}$-pyrroline-5-carboxylate synthetase (P5CS) [14].

\subsection{Effect of pH soaking on the content of total amino acid and GABA}

\subsubsection{Total content of free amino acid}

In general, $\mathrm{pH}$ of the soaking solution did not significantly affect the total content of free amino acid during germination (Figure 4a). An exception was observed at pH 5.3 after 12 hours germination, where the content of free amino acid was the highest and also significantly higher than those at the other two $\mathrm{pH}(6.3$ and 7.3).

\subsubsection{GABA content}

(4a)

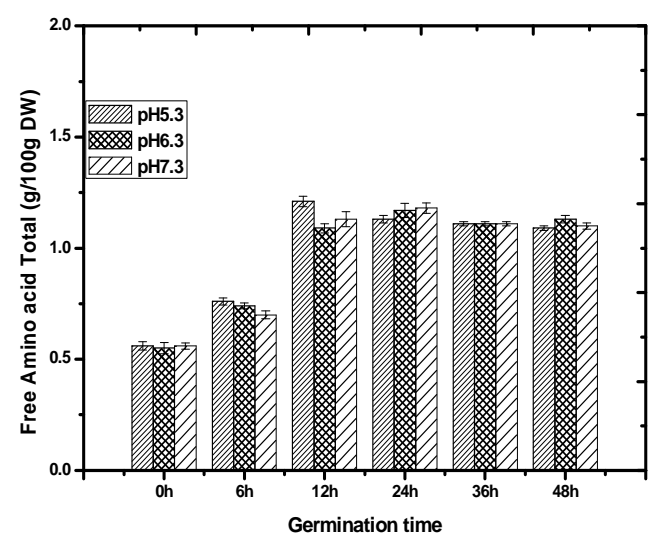

(4b)

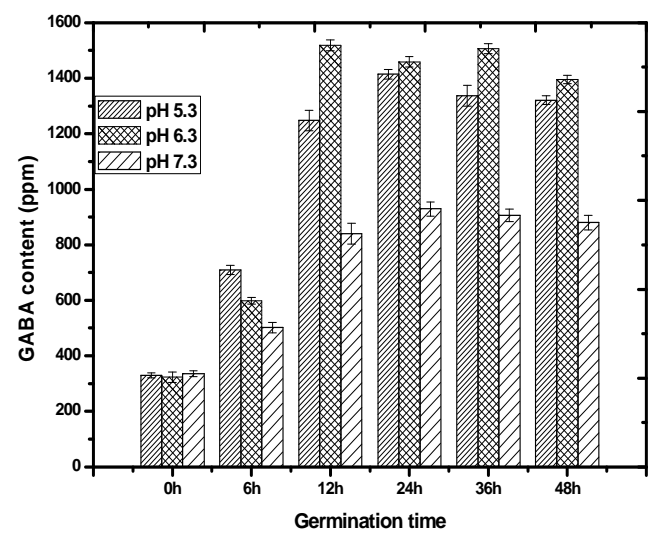

Figure 4. The change of total content of free amino acid (4a) and GABA content (4b) in the germinated mung bean under $\mathrm{pH}$ control (under hypoxia-anaerobic condition).

Effect of soaking $\mathrm{pH}$ on GABA content was studied under hypoxia-anaerobic condition at $35{ }^{\circ} \mathrm{C}$ and the results were showed in Figure $4 \mathrm{~b}$. By other way, germination time had also significant effect on the GABA amount. The highest GABA of soaking pH of 7.3 and 5.3 was reached $969.28 \mathrm{ppm}$ and $1414.64 \mathrm{ppm}$, respective, after 24 hours and slightly decreased in prolonged germinated time then. The highest GABA $1519.07 \mathrm{ppm}$ were achieved at soaking $\mathrm{pH}$ 6.3 after 12 hours of germination, keep stable to 36 hours of incubation and then slightly decrease. Many previous researches showed the higher $\mathrm{pH}$, the lower GABA contain in germinated seed. The optimal $\mathrm{pH}$ to boost GABA content in germinated brown rice was from 3.0 to 5.8 [19]. By the other results, GABA content was highest at pH 5.6 and lowest at pH 8.4 [20]. In addition, Gou et al. [13] revealed the highest GABA in germinated soybean contain at $\mathrm{pH}$ 6.0. They also showed that these are many factors impact to the level of GABA such as: germination time, germinated condition combined with $\mathrm{pH}$ soaking. In our results, the lowest 
GABA content was $\mathrm{pH} 7.3$, with agreement some previous studies above. The main reason was explained by Busch \& Fromm [12] that the optimal $\mathrm{pH}$ of enzyme reaction for GABA degradation was from 8.6 to 9.5 under hypoxia condition. However, the highest GABA content was $\mathrm{pH}$ 6.3, while the GABA content at $\mathrm{pH} 5.3$ was lower than and had the same trend compared to $\mathrm{pH}$ 7.3. This can be explained that optimal $\mathrm{pH}$ for germinating mung bean under hypoxia-anaerobic condition may be approximately 6.3. As many researches proved that $\mathrm{pH}$ had an important role in accumulating GABA by the way enhancing the activity of glutamic acid decarboxylase (GAD), diamine oxidase (DAO) and other related enzymes such as arginine decarboxylase (ADC) and ornithine decarboxylase (ODC) [20]. According to Kurkdjian \& Guern [21], $\mathrm{pH}$ in cytoplasm decreased by 0.4 to 0.8 , so maybe the real value of $\mathrm{pH}$ in cytoplasm in germinated mung bean lower 6.3 and also higher 5.3 which created an optimal $\mathrm{pH}$ condition for accumulating GABA.

\subsection{Optimizing GABA content under hypoxialanaerobic condition}

Table 1. Ranges of the three independent variables used for the optimization of germination conditions on the accumulation of $\gamma$-aminobutyric acid of mung bean.

\begin{tabular}{|l|c|c|c|c|}
\hline \multirow{2}{*}{ Symbol } & \multicolumn{3}{|c|}{ Code levels } \\
\cline { 3 - 5 } & & -1 & 0 & -1 \\
\hline Temperature $\left({ }^{\circ} \mathrm{C}\right)$ & $\mathrm{X}_{1}$ & 32 & 35 & 38 \\
\hline Time (hours) & $\mathrm{X}_{2}$ & 9 & 12 & 15 \\
\hline $\mathrm{pH}$ & $\mathrm{X}_{3}$ & 5.8 & 6.3 & 6.8 \\
\hline
\end{tabular}

Table 2. Experiment date for GABA content from germinated mung bean.
Table 3. Analysis of variance (ANOVA) for the regression equation.

\begin{tabular}{|c|c|c|c|c|c|c|c|c|}
\hline No. & $\mathrm{X}_{1}$ & $\mathrm{X}_{2}$ & $\mathrm{X}_{3}$ & GABA(ppm) & & & & \\
\hline 1 & 32 & 9 & 5.8 & 1353.43 & & Coeff. SC & Std. Err. & $\mathrm{P}$ (value) \\
\hline 2 & 38 & 9 & $\begin{array}{ll}5.8 \\
5.8\end{array}$ & 1412.26 & Constant & 1520.85 & 15.1202 & $4.81 \mathrm{E}-15$ \\
\hline$\frac{3}{4}$ & $\frac{32}{38}$ & $\begin{array}{l}15 \\
15\end{array}$ & $\begin{array}{l}5.8 \\
5.8\end{array}$ & $\begin{array}{l}1468.21 \\
1589.22\end{array}$ & $\mathrm{X}_{1}$ & 81.9616 & 11.086 & $4.13 \mathrm{E}-05$ \\
\hline 5 & 32 & 9 & 6.8 & 1024.2 & $X_{2}$ & 104.266 & 11.086 & $5.95 \mathrm{E}-06$ \\
\hline 6 & 38 & 9 & 6.8 & 1217.52 & $\mathrm{X}_{3}$ & -128.233 & 11.086 & $1.05 \mathrm{E}-06$ \\
\hline 7 & 32 & 15 & 6.8 & 1144.22 & $\mathrm{X}_{1}^{2}$ & -64.9662 & 9.90952 & 0.000104 \\
\hline 8 & 38 & 15 & 6.8 & 1225.62 & $\mathrm{X}_{2}^{2}$ & -78.4278 & 9.90952 & $2.41 \mathrm{E}-05$ \\
\hline $\begin{array}{l}9 \\
10\end{array}$ & $\begin{array}{l}29.954 \\
40.046\end{array}$ & $\begin{array}{l}12 \\
12\end{array}$ & $\begin{array}{l}6.3 \\
6.3\end{array}$ & $\begin{array}{l}1217.24 \\
1475.38\end{array}$ & $\mathrm{X}_{3}{ }^{2}$ & -95.405 & 9.90953 & 4.90E-06 \\
\hline 11 & 35 & 6.954 & 6.3 & 1078.28 & $\mathrm{X}_{1} \mathrm{X}_{2}$ & -35.0551 & 15.3868 & 0.0487 \\
\hline 12 & 35 & 17.046 & 6.3 & 1538.17 & $X_{1} X_{3}$ & -16.9777 & 15.3868 & 0.298483 \\
\hline 13 & 35 & 12 & 5.459 & 1489.26 & $\mathrm{X}_{2} * \mathrm{X}_{3}$ & -49.2901 & 15.3868 & 0.010772 \\
\hline 14 & 35 & 12 & 7.141 & 1031.13 & & & & Cond. no. \\
\hline$\frac{15}{16}$ & $\frac{35}{25}$ & 12 & 6.3 & $\begin{array}{l}1519.16 \\
152523\end{array}$ & $\mathrm{~N}=19$ & $\mathrm{Q}^{2}=$ & 0.814 & $=4.0445$ \\
\hline$\frac{10}{17}$ & $\frac{35}{35}$ & $\begin{array}{l}12 \\
12\end{array}$ & $\begin{array}{l}6.3 \\
6.3\end{array}$ & $\begin{array}{l}1525.23 \\
1524.32\end{array}$ & $\mathrm{DF}=9$ & $\mathrm{R}^{2}=$ & 0.982 & $\mathrm{Y}$-miss $=0$ \\
\hline 18 & 35 & 12 & 6.3 & 1518.11 & & & RSD & Conf. lev. \\
\hline 19 & 35 & 12 & 6.3 & 1516.67 & & & $=3$ & $=0$. \\
\hline
\end{tabular}


Table 4. Arrangement and result of confirmatory trials.

\begin{tabular}{|l|c|c|c|l|}
\hline & Temperature $\left({ }^{\circ} \mathrm{C}\right)$ & Time (hours) & $\mathrm{pH}$ & GABA (ppm) \\
\hline Predicted value & 36.551 & 14.52 & 5.83 & 1646.29 \\
\hline Actual value & 36.6 & 14.5 & 5.83 & 1638.67 \\
\hline
\end{tabular}

The second- order polynomial model describing the correlation between GABA content and the three variables in this study was obtained in Eq. (2) below:

$$
\begin{aligned}
& Y=1520.85+81.9616 X_{1}+104.266 X_{2}-125.233 X_{3}-35.0551 X 1 X 2-49.2901 X_{2} X_{3}-64.9662 X_{1}^{2} \\
& -\mathbf{7 8 . 4 2 7 8}_{2}^{2}-\mathbf{9 5 . 4 0 5 X _ { 3 } ^ { 2 }}(2)
\end{aligned}
$$

The statistical analysis (Table 3 ) indicated that the proposed model was adequate with a satisfactory value of $\mathrm{R}^{2}(0.982)$. The value of the adjusted determination coefficient (Adj. $\mathrm{R}^{2}=$ 0.964) was also very large, which indicated a high significance of the model. The F-value of 2.912 was lower than the value of tabulated $F_{0.05(11,5)}=3.268$. This result implied that the regression model was most significant $(\mathrm{p}<0.05)$.

In order to evaluate the precision and accuracy of the above model, the optimal combination of experiments and a randomly selected combination for GABA accumulation within the scope of the variables were investigated. The arrangement and results of the confirmatory trials were shown in Table 4. The observed content of GABA in soybean germination under the optimal conditions was $1638.67 \pm 21.2 \mathrm{ppm}$, which was quite close to the predicted value of $1646.29 \mathrm{ppm}$ in the model. The experimental results proved that the model was valid.

\section{CONCLUDING REMARKS}

As shown in this study, the content of GABA in germinated mung bean was significantly enhanced during germination by manipulating some external factors. Previous publication studies indicated many ways to increase GABA content, including heat shock, water stress, darkness, mechanical stimulation, hypoxia and phytohormones etc. The current research reported a simple method to increase GABA content by combining hypoxia/anaerobic conditions with germination time, temperature and soaking $\mathrm{pH}$ for germinating mung beans. The results showed the highest GABA content of $1519.07 \mathrm{ppm}$ was observed after 12 hour germination in the soaking $\mathrm{pH}$ of 6.3 at $35^{\circ} \mathrm{C}$. This figure was 25.32 times as high as the dried mung beans. By RSM, the optimal conditions for GABA accumulation in germinated mung bean were obtained: temperature, $36.6^{\circ} \mathrm{C}$; time, 14.5 hours; and $\mathrm{pH}, 6.3$. Compared with the predicted highest GABA yield, $1646.29 \mathrm{ppm}$, a highest GABA yield of $1638.67 \mathrm{ppm}$ was obtained in this experiment when the designed conditions were carried out, and the two data were close to each other. The results proved that the designed model was valid. The study also suggested that germinated mung bean can be used as a potential source of GABA-enriched foods. Based on the results of this study, future researchers can further identify the starting time of the hypoxia and anaerobic during germination.

Acknowledgement: This research was funded by HCMC University of Technology under grant number TSĐH-2015-KTHH-64. 


\section{REFERENCES}

1. Abdou A. M., Higashiguchi S., Horie K., Kim M., Hatta H., and Yokogoshi H. Relaxation and immunity enhancement effects of gamma-aminobutyric acid (GABA) administration in humans, Biofactors 26 (2006) 201-208.

2. Vidal-Valverde C., Frias J., Sierra I., Blazquez I., Lambein F and Kuo Y. - New functional legume foods by germination: effect on the nutritive value of beans., lentils and peas. European Food Research and Technology 215 (6) (2002) 472-477.

3. Alonso R., Orue E., Marzo F. - Effect of extrusion and conventional processing methods on protein and antinutritional factor contents in pea seeds. Food Chemistry 63 (1998) 505512.

4. Moongngarm A., and Saetung N. - Comparison of chemical compositions and bioactive compounds of germinated rough rice and brown rice. Food Chem. 122 (3) (2010) 782788.

5. Mubarak A. E. - Nutritional composition and antinutritional factors of mung bean seeds (Phaseolus aureus) as affected by some home traditional processes. Food Chem. 89 (4) (2005) 489-495.

6. Kim H. Y., Yokozawa T and Nakagawa T. - Protective effect of $\gamma$-aminobutyric acid against glycerol-induced acute renal failure in rats. Food and Chemical Toxicology $\mathbf{4 2}$ (2004) 2009-2014.

7. Kasarin T., Pairoj L., Warunee V., and Chanida H. - GABA (Gamma-amino butyric acid) production of mung bean (Phaseolus aureus) during germination and the cooking effect. Suranaree J. Sci. Technol. 21 (4) (2014) 307-313.

8. Shelp B. J., Brown A. W. and McLean M. D. - Metabolism and functions of gammaaminobutyric acid, Trends in Plant Science 4 (1999) 446-452.

9. Veluppillai S., Nithyanantharajah K. and Vasantharuba S. - Biochemical Changes Associated with Germinating Rice Grains and Germination Improvement, Rice Science 16 (3) 240-242.

10. Rodriguez C., Frias J., Vidal-Valverde C. and Hernandez A. - Correlations between some nitrogen fractions, lysine, histidine, tyrosine, and ornithine contents during the germination of peas, beans, and lentils, Food Chemistry 108 (1) (2008) 245-252.

11. Moore S. and Stein W.H. - Photometric ninhydrin method for use in the chromatography of amino acids, J. Biol. Chem. 176 (1) (1948) 367-388.

12. Zhang Q., Xiang J., Zhang L., Zhu X., Evers J., Werf W., and Duan L. - Optimizing soaking and germination conditions to improve gamma-aminobutyric acid content in japonica and indica germinated brown rice, Journal of functional foods 10 (2014) 283291.

13. Guo Y. X., Chen H., Song Y. and Gu Z. X. - Effects of soaking and aeration treatment on $\gamma$-aminobutyric acid accumulation in germinated soybean (Glycine max L.), European Food Research and Technology 232 (5) (2011) 787-795.

14. Nonogaki H., Bassel G. W., and Bewley J. W. - Germination-still a mystery, Plant Science 179(6) (2010) 574-581. 
15. Yang R., Guo Q. and Gu Z. - GABA shunt and polyamine degradation pathway on $\gamma$ aminobutyric acid accumulation in germinating fava bean (Vicia faba L.) under hypoxia, Food Chemistry 136 (2013) 152-159.

16. Aurisano N., Bertani A. and Reggiani R. - Anaerobic accumulation of 4-aminobutyrate in rice seedlings; causes and significance. Phytochemistry 38 (5) (1995) 1147-1150.

17. Yeap S. K., Beh B. K., Mohd Ali N., Mohd Yusof H., Ho W. Y., Koh S. P., Alitheen N. B., and Long K. - In Vivo Antistress and Antioxidant Effects of Fermented and Germinated Mung Bean, BioMed Research International, (2014), Article ID 694842.

18. Xu Y., Shi G. X., Ding C. X., and Xu X. Y. - Polyamine metabolism and physiological responses of Potamogeton crispus leaves under lead stress, Russian Journal of Plant Physiology 58 (3) (2011) 460-466.

19. Saikusa T., Horino T. and Mori Y. - Accumulation of $\gamma$-aminobutyric acid (GABA) in the rice germ during water soaking, Bioscience, Biotechnology, and Biochemistry 58 (1994) 2291-2292.

20. Reggiani R., Hochkoeppler A., and Bertani A. - Polyamines in rice seedlings under oxygen-deficit stress, Plant Physiol. 91 (1989) 1197-1201.

21. Kurkdjian A and Guern J. - Intracellular $\mathrm{pH}$ : Measurement and importance in cell activity, Annual Review of Plant Biology 40 (1) (1989) 271-303. 